\title{
Lexical Choices and Ideology in Translation: A Case Study of 'The old Man and the Sea
}

\author{
*Maryam Najafian, Ahmad moinzadeh \\ University of Isfahan, Isfahan, Iran \\ *m.najafian56@yahoo.com,
}

\begin{abstract}
The present research aims at conducting a critical study of the novel 'The Old Man and the Sea' written by Ernest Hemingway (1976) and its two translated versions in Persian; one rendered by Faramarzi (2006) the other by Shahin (1979). The researchers apply a comparative lexical analysis proposed by Newmark (1988) and Venuti (1995). An attempt has been made to reveal the ideology behind the original sample words and to show how translators and the effect thereof handle it. The data of this research consists of 10 ideological laden terms selected randomly among 45 words from the original text and the corresponding Persian translations. The results of this study suggest a significant difference between the two Persian translations and the original novel. It revealed that one of the translators has attempted to 'domesticate' his translation while another has been attentive to 'foreignize' it. As for implication, it seems necessary to note that translational decisions made by actual translators under different socio-cultural and ideological settings in real life and real situations should be considered. The perlocutionary consequences resulted from adoption of such decisions are of importance.
\end{abstract}

Key Words: Literary translation, Ideology, Lexical Choices, Critical discourse analysis

\section{Introduction and Literature Review}

Landers (2001) states that literary translation is the most demanding type of translation because "how one says something can be as important, sometimes more important, than that one says." According to Sanchez (2009), "if any kind of translation implies a challenge, in the case of literary translation the challenge is ever greater because the translator has to contend not only with semantic problems but also with the stylistic connotations inseparable from the content which will demand a constant and painful process of decision making." Newmark (1988) believes that lexical translation is more complicated task. The various techniques and procedures of componential analysis can at least show the translator how to redistribute SL sense-components in the TL. He states that "in contrast to translation methods, which relate to whole texts, translation procedures are used for sentences and the smaller units of language within the text" (ibid.). He goes on to refer to the following procedures of translation:

- Word-for-word translation: in which the SL word order is preserved and the words translated singly by their most common meanings, out of context.

- Literal translation: in which the SL grammatical constructions are converted to their nearest TL equivalents, but the lexical words are again translated singly, out of context.

- Faithful translation: it attempts to produce the precise contextual meaning of the original within the constraints of the TL grammatical structures.

- Semantic translation: which differs from 'faithful translation' only in as far as it must take more account of the aesthetic value of the SL text.

- Adaptation: which is the freest form of translation, and is used mainly for plays (comedies) and poetry; the themes, characters, plots are usually preserved, the SL culture is converted to the TL culture and the text is rewritten.

- Free translation: it produces the TL text without the style, form, or content of the original.

- Idiomatic translation: it reproduces the 'message' of the original but tends to distort nuances of meaning by preferring colloquialisms and idioms where these do not exist in the original.

- Communicative translation: it attempts to render the exact contextual meaning of the original in such a way that both content and language are readily acceptable and comprehensible to the readership (1988b).

Newmark (1988) distinguishes between communicative and semantic translation. According to him communicative translation aims to affect TT reader as the same as the impact on ST reader by original text. Semantic translation attempts to transfer the contextual meaning of ST. He gives "literal translation 
priority in both communicative and semantic translation and only where semantic translation risks equivalent effect or leads to unidiomatic structures communicative translation should be applied" (ibid.). Lefever (1985) points out that ideology is a specific imagination of what the world should be like", but it is also "the world view of a certain society at a certain moment" (ibid). According to Fawcett (1998)",'throughout the centuries, individuals and institutions applied their particular beliefs to the production of certain effect in translation." Chesterman (1998) alerts us to the fact that empirical translation theory cannot be satisfied with the belief that the target text, or the translator, is entirely determined by external causes: "translators are also agents of change, not just passive recipients of causal impulses" (Crisafulli, 2004). Mennheim (1994) believes that, "ideological element in human thought [...] is always bound up with the existing life-situation of the thinker [...] human thought arises and operates, not in a social vacuum but in a definite social milieu". Schaffner (2003) claims that:

The relationship between ideology and translation is multifarious. Any translation may be reproduced as ideological since the choice of a source text and the use to which the subsequent target text is put is determined by the interests, aims, and objectives of social agents. However, ideological aspects can also be determined within a text itself, both at the lexical and grammatical levels. According to Herman (1985), all translation contains a degree of changing of the original text for a given purpose. Supporting his claim, Tompson (1984) argues, "the study of ideology is inseparable from the social-historical analysis of the forms of domination which meaning serves to sustain." Bassnett and Lefever (1998) define the relation between power and translation as; "translation is always enmeshed in a set of power relations that exist in both the source and target contexts, the problem of decoding a text for a translator involves so much more than language despite the fact that the basis of any written text is its language".

When one choose a word they do more than name an object, person or situation, they also convey feelings about what are being described. Feeling is an important part of meaning. Words can change the beliefs of people. When ideology leads to action, the choice of the words is important. It is believed that words are the major population groups in the text and their social worlds. The translators are in a position to explore how they function as participants in clauses as parts of those worlds. Van Dijk (1998) points out that relationship between language, power and ideology are very complex issues than they may seem to be. If translators were aware of these complexities, their works will be better. Lefever (1992) considers translation as a rewriting of ST, which definitely entails ideologically motivated manipulation. Schäffner (2003) claims that "all translations are ideological since the choice of a source text and the use to which the subsequent target text is put is determined by the interests, aims and objectives of social agent".

An important aspect of the present study is the connection of Critical Discourse Analysis and translation. The main aim of performing such a detailed critical analysis of the lexis of a text and its two corresponding translation versions is to reveal patterns, which might be cues to the underlying ideology. Hatim and Mason (1997) propose a model to assess the translated works. They consider the sets of constraints relating to genres, discourse and text as semiotic systems within which the expression of ideology occurs. According to Mason (1994), "the investigation of ideology in translation is best handled within such a framework. the linguistics-oriented approaches to translation studies have failed to address the concept of ideology through years of their prevalence, because such approaches are limited to their scientific models for research and the empirical data they collect", so that in Venuti (1998a) words "they remain reluctant to take into account the social values (and ideologies) that enter into translating as well as the study of it."

Van Dijk (1998) defines ideology as "the set of factual and evaluative beliefs_ that is the Knowledge and the opinions_ of a group with an emphasis on socially dominant groups capable of imposing their sets of beliefs on others", or else groups challenging generally accepted social beliefs in an "ideology of resistance" (ibid). A translator, just like an author, is not simply a person but a socially and historically constituted subject. Robinson (2001) sees translators as follow: Translators [...] are those people who let their knowledge govern their behavior. In addition, that knowledge is ideological. It is controlled by ideological norms. If you want to become a translator, you must submit to the translator's submissive role, submit to being possessed by what ideological norms inform you. It seems that translators are not usually aware of ideological factors governing their process of the source text interpretation. These ideological impacts on rendering ST may result in TT that has a local or foreign flavor. According to Venuti (1995), translation can reconcile the differences that separate languages and cultures. The deficiency of old linguistics-based approaches - which "are mainly descriptive studies focusing on textual forms" (cited in Calzada-Pérez, 2003) - in accounting for social values in translation and other aspects of 
language use resulted in developing a new trend of research called Critical Discourse Analysis (CDA) "whose primary aim is to expose the ideological forces that underlie communicative exchanges [like translating]" (Calzada-Pérez, 2003-).

According to Venuti (1995), distinction between a foreignizing and a domesticating strategy is mostly associated with the German philosopher and protestant theologian. Hatim (1997) states that "domestication means negotiating the discoursal, generic and textual designs of the source text in terms of the target norms and conventions", whereas "foreignization means negotiating these values in terms of source language norms and conventions". Elaborating his claim, Venuti (1995) points out that over the last three centuries or so the predominant trend in Anglo-American translations has been 'domestication'. According to Hatim and Mason (1997), "the result of applying such a strategy has been depriving source text producers of their voice and re-expressing foreign cultural values in terms of what is familiar to the dominant culture". This may have the effect of to assimilate to a dominant or even hegemonic culture all that is foreign to it. The problem arises when most of literary works translated to Persian cannot evoke the same reaction in the target language as it did in its original form in the source language. The significance of this study is to show how ideological manipulation by the translators and social relations may affect the understanding of literary works. Due to abovementioned problems, the present study will address the following research questions:

- Which kind of translation strategies, domestication or foreignization proposed by Schleiermacher (2000), are used to render the English novel 'the Old Man and the Sea' in these two corresponding Persian versions?

- Which kind of translation strategies, ranging from word for word translation to communicative translation proposed by Newmark (1988), are used to render the English novel 'the Old Man and the Sea' in these two corresponding Persian versions?

- Is there any ideological significance in using lexical resources in English version?

- Whether translation affects the ideological output of the original text?

Sertkan (2007) analyzed the ideology of lexical choices in the Turkish translations of "Oliver Twist". He carried out a descriptive critical analysis of lexical choices in five Turkish translated versions of the mentioned novel. Lisans-tezi (2008) analyzing of two Turkish versions of "The Old Man and The Sea" believes that variations exist between them in terms of semantic, syntactic and stylistic features. Concerning the problematic factors involves in translation such as form, style, proverbs and idioms; Shafieie and Hatam (2009) conducted a comparative study of "The Old Man and The Sea" with its two Persian Translations. The present study examines Ernest Hemingway's novel, The Old Man and the Sea, a novel originally produced in English (1952), and its two Persian translations, Piremard va Darya, one rendered by Faramarzi (2006) and another one by Shahin (1979) by applying a comparative lexical analysis proposed by Newmark (2003) and Venuti (1995). Furthermore, this study focuses on one textual feature -i.e. lexical choices- and the extent they represent ideological orientations wherever the target text diverges from the source text. The extent to which the translators may regard foreign words in original English version as manifestations of ideological orientations has been the researchers' concern. Such an attempt, to the best of the researchers' knowledge, is rare in the realm of translation critical studies. The rationale behind choosing the English source text 'the Old Man and the Sea' to be compared with its respective Persian translations is that, this work is hailed as one of the greatest works of world literature. The data of this research consists of 10 words have been chosen among 45 ideologically laden words in the original texts and comparing them critically with their corresponding translation units in Persian. CDA is used as a methodological tool for the identification of the 'manipulation'.

Ideology and Translation: It is believed that ideology can be detected in lower level linguistic units such as lexical choices or lexical expression in literary texts. A linguistic approach leads to some productive conclusions when investigating ideological distortion in translation. There is a need for a critical approach to analyze the ideological relations in this kind of text. Ideological- biased mental models of translator and even publisher of one special work affect a communicative situation of it. In order to highlight the differences in translated versions, and hence the image of Hemingway, avoiding at the same time any judgments, it is preferred to have a look at the ideological characteristics of this author as the main actor in the network of writing and translating.

A Brief Biography of Ernest Hemingway: Ernest Hemingway grew up outside a suburb of Chicago, spending summers with his family in rural Michigan. After high school, he got a job writing for The Kansas 
City Star, but left The Star after only six months to join the Red Cross Ambulance Corps during World War I, where he was injured and awarded the Silver Medal of Military Valor. Afterward, he lived in Ontario and Chicago, where he met his first wife, Hadley Richardson. In 1921, they moved to Paris, where he began a long friendship with F. Scott Fitzgerald and other ex-patriot American writers of the "lost generation". After the 1926 publication of his first novel, The Sun Also Rises, Hemingway divorced Hadley, married Arkansas native Pauline Pfeiffer, and moved to Florida. Hemingway's father committed suicide in 1928, shooting himself. During the Spanish Civil War, Hemingway moved to Spain to serve as a war correspondent, a job that inspired his famous 1939 novel For Whom the Bell Tolls. After its publication, he met his third wife, Martha Gellhorn. In 1946, Hemingway married his fourth and final wife, Mary Hemingway, and the couple spent the next 14 years living in Cuba. After a final move to Idaho, Hemingway took his own life in 1961, leaving behind his wife and three sons. Living in Cuba in the late 1940s, one of Hemingway's favorite pastimes was fishing in his boat,

The Pilar. This simple pastime contrasted greatly with the turbulent events of his life that preceded his time in Cuba. Hemingway served in World War I and World War II and witnessed the liberation of Paris and the 1945 schism within the Cuban Communist party. Having viewed death and hardship in many forms, Hemingway's feeling of disillusionment was only magnified by his 10-year struggle with writing that preceded the publication of 'The Old Man and the Sea'. 'The Old Man and the Sea' was the last major work of fiction Hemingway wrote. It won the Pulitzer Prize in 1953 and contributed to Hemingway's selection for the Nobel Prize in 1954. (Extracted from www.litcharts.com) Sidiropoulou (2005) states that Hemingway tends to use simple linguistic structures over compound or complex ones, simple diction, avoidance of any rhetorical embellishments, and a marked preference for the laconic and even telegraphic sentences. He presents the material without explanation, rationalization, or interpretation. It is the readers as well as the translators' job to understand and explain.

Vocabulary Choices and Ideology: Hemingway has been used his personal experiences to write this novel. His indescribable interest on fishing and his familiarity with 'kujimar' village, angler and prico's bodagage has had impact on creating the masterpiece 'the Old Man and the Sea'. It seems that this book is under the influence of the author's interest and familiarity with coastal zone and people of Cuba. The characteristic of Santiago is analogous to Hemingway himself and his contents during his life that at last end with defeat. Choosing some, ideological laden terms all during the novel imply the factors that have dominance on the mind of the author. Hemingway was not really writing about fishing at all. He was writing about life, the continuous struggles we are all faced with, the hard knocks, the dreams, the disappointments, and ultimately the fact that you just have to keep going because that is what we are here for. For our analyzing, the translation of Faramarzi is considered as TT1, and Shahin's translation as TT2. Following is the detailed ideological analysis of 10 ideological laden words in this novel.

\section{Ideologically Laden Terms}

Salao: It is a Spanish word, which represents the nationality of the boy in this novel and shows the interest and familiarity of the author to this language and the people who live in Cuba with Spanish originality.

ST:"But after forty days without a fish the boy's parents had told him that the old man was now definitely and finally salao, which is the worst form of unlucky...

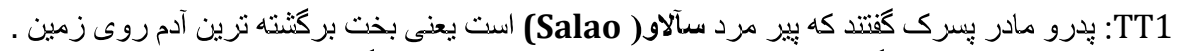

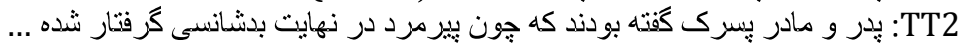

In TT1, the translator has used the transliteration method with the original word to preserve the ideology behind choosing this word to show the nationality of the boy and foreignizing it; but the translator inTT2 totally has omitted the original word; therefore, there is no trace of the originality of the boy. The latter is a kind of domestication by ignoring the original word to ease the reading process of the novel for Persian readers.

Queva : ST: Que va,. The boy said. .There is many good anglers and some great ones. However, there are only you.

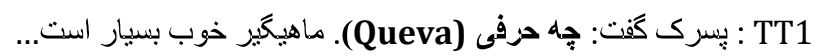




$$
\text { .... خوب ، ماهيكيران خوب و كاهى هم معزوف : TT2 }
$$

In TT1, the translator has used the referential meaning of the word with the original word inside parenthesis to preserve the ideology behind choosing this word to show the nationality of the boy; but the translator inTT2 has used free translation method and totally omitted the original word; therefore, there is no trace of the originality of the boy.

Terrace: ST: He used to come to the Terrace_sometimes too in older days...

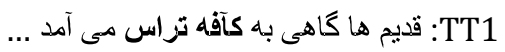

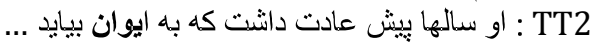

The original word has a root in the experience of Hemingway himself and his familiarity with this Café in Cuba and his belief that it is a recognized place for all in that country. The translator in TT1 has used literal translation by adding the explanatory component ' 'كافه ' to transparent the whole meaning as a place. The translator in TT2 has totally omitted the word and replaced it with the word 'ايوان' that is more familiar to the Persian receivers. The latter is a kind of domestication and by this; the translator has distorted the meaning of the original and the intention of the author.

Elmar: ST: They spoke of her as el mar, which is masculine.

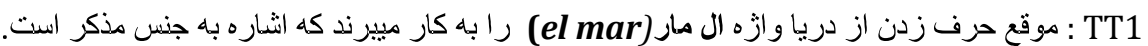

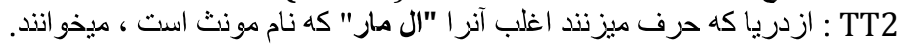

The author of this novel himself has used the objective pronoun, "her", in order to write about "sea "; hence his idea about sea as feminine is analogous to that of the old man. The word "el mar" is the Spanish word, which has been used, in the original novel. It is a culture bound term which used by special kind of Spanish people who are fishing. It refers to masculinity. In TT1, the translator has used transference method as well as transcription to foreignizing the target text. In TT2, the translator has used transliteration method and pointed to the original word in footnote. There is a mistranslation of the word "masculine" in TT2.

Bodega: St: "Perico gave it to me at the bodega", he explained.

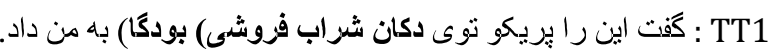

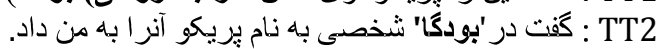

The origin of this word is "a wine shop", from L. apotheca, from Gk. apotheke "depot, store" (see apothecary). This word has more application in Spain due to that marlin has used it. It is a culture bound term (extracted from www. dictionary.reference.com).The translator in TT1 has used semantic method as well as transcription for domesticating it in order to be more perceptible to target text receivers. The translator in TT2 has used transference method in order to 'foreignize' it.

Gulf Stream: ST: He was an old man who fished alone in a skiff in the Gulf Stream...

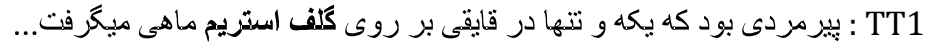

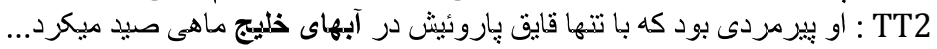

European discovery of the Gulf Stream dates to the 1513 expedition of Juan Ponce de León, after which it became widely used by Spanish ships sailing from the Caribbean to Spain. Tropical cyclone formation is common over the Gulf Stream, especially in the month of July. Such storms have the potential to create strong winds and extensive damage (extracted from www.sailblogs.com). In TT1, the translator has applied transliteration method for foreignizing it. In TT2, the translator has applied free translation to domesticate it.

The great Di Maggio: ST: Have faith in the Yankees my son. Think of the great DiMaggio.

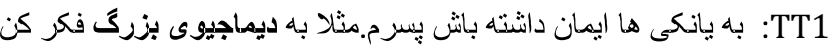

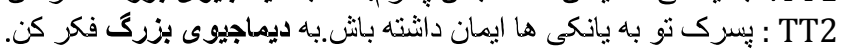


'Di Maggios' was one of the best baseball players in New York, He played for Yankee team. His father (Giuseppe) was a fisherman, as were generations of 'Di Maggios' before him. The author has wanted to introduce him to people around the whole world because he himself has liked him and looked at him as a hero. Joe DiMaggio represents many things to the old man. He is one whose father was a poor fisherman just like he is. When he was out fishing, he thought to himself, would the great DiMaggio ever stay this long as he did and quickly replied to himself that DiMaggio is young and strong and that his father was a fisherman so of course he would stay. This made him feel better because now he could compare himself to his hero (www.expriencefestival.com). In TT1 as well as TT2, both translators transliterate it and put it on the shoulder of the reader to understand who 'Di Maggio' is without any explanation or footnoting or bringing it with its respective explanation on the appendix part. Both translators have applied semantic method without considering what is on the mind of the author for bringing this name in his novel. The researchers propose to use

$$
\text { "ديماجيو قهزمان بزرك بيس بال" }
$$

The Sacred Heart of Jesus: ST: there was a picture in color of the Sacred Heart of Jesus and another of the Virgin of Cobre.

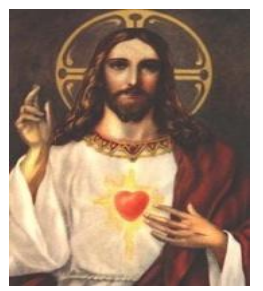

$$
\begin{aligned}
& \text { TT1 ..... عكس رنكگى قلب مقدس مسيح و عكسهاى ديكرى از باكزه كوبر آويخته بود. }
\end{aligned}
$$

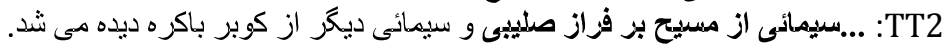

Since the heart of Jesus appears to Christians as the sensible sign of his love, the visible wound in the heart will naturally recall the invisible wound of this love. This symbolism also explains that the devotion, although giving the heart an essential place, is but little concerned with the anatomy of the heart or with physiology (www.newadvent.org). It shows the deep faith of the old man's wife. It has an ideological meaning for the author. There exists no picture in the original novel; it is on the part of the translators to make it tangible for the Persian receivers if not it leads to domestication. In TT1, the translator has used literal translation in order to transfer the semantic meaning, the exact contextual meaning of the original .In TT2, the translator has mistranslated it due to his lack of knowledge about the culture of Spain and the ideological meaning that has been hidden in these words. The researchers propose the communicative strategy for making the thought and cultural content of the original more accessible to the reader by adding some explanatory components to it.

Virgin of Cobre: ST: there was a picture in color of the Sacred Heart of Jesus and another of the Virgin of Cobre.

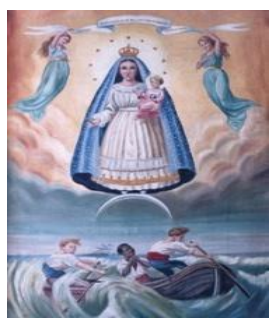

$$
\text { 2. : . . . . . . . TT1 }
$$

The town of El Cobre was founded in 1550 as a Spanish copper mine, worked by slaves and Indians. One day in 1608, two Indians and a slave boy were gathering salt on the coast near El Cobre when they saw something floating in the water. It was a small statue of the Virgin Mary, carrying the Christ child and a gold cross. She floated on a board bearing the inscription, Yo soy la Virgen de la Caridad, "I am the Virgin of Charity. The Virgin has collected many votive offerings from her grateful worshippers over the years. In the 1950s, Ernest Hemingway gave the Virgin the Nobel Prize for Literature he won after writing The Old Man and the Sea in Havana (extracted from www.sacred-destinations.com). 
It is important for translators to know about the characteristics of this sacred picture. It is a culture bound term, and then if we transfer it without any explanation or footnote, the reader cannot receive the actual value of it as it is for Hemingway as well as the old man. This is an ideological loaded term. In TT1, the translator has transliterated this word; then he foreignized it and put it on the reader to extract the meaning of it. In TT2, the translator has mistranslated it by changing the position of two words (shift).

Deep Well: ST: I worked the deep wells for a week

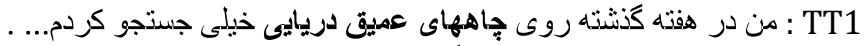

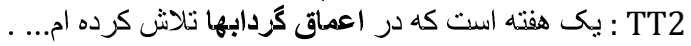

Deep wells refer to the characteristic of Gulf Stream, which is almost stormy all during the year. According to etymological dictionary, it means "to spring, rise, gush", 0.E. wiellan (Anglian wællan), causative of weallan "to boil, bubble up". One who knows the Gulf Stream can translate it perfectly. After the storm, the sea is covered with bubbles; then most of the fishes swim up to the surface to get more oxygen. This is a good time for fishing. In TT1, the translator translate it word for word and the second translator mistranslate it by using transposition method and considering the adjective "deep" as noun "اعماق"

\section{Conclusion}

The result of such a study has shown that the choice of vocabulary may display the characteristics of participants in the novel and hence, may reveal the ideological positions and conflicts. In this article, it was argued that the comparative analysis of two Persian versions of the same English novel produced in the same cultural settings with 27 years intervals may contribute to identifying different views of the translators and the society thereof as well as the ideological choices that underlie such views. According to Goatly (2000), critical reading can benefit greatly from linguistic analysis, precisely because it brings to light what is ordinarily latent or hidden. Literary works with respect to their specific features, aesthetic and expressive, are more difficult to translate than other types of text. In translation of such texts, there is only a fade borderline between semantic and communicative translation. CDA Scholars believe that all usage of language, including translation, is ideological and this means that translation is always a site for ideological manipulations. One can examine the ideological aspects in the process of text production (translating) and the role of the translator as a target text producer as well as a source text interpreter. This may concern with the ways in which different viewpoints may be created using lexicons in particular points of time in the same cultural context.

Functionalist approaches try to dethrone the source text itself by emphasizing the role of the translator as a creator of the target text and giving priority to purpose of producing target text. By considering the importance of decision-making in translation, it seems that the researchers on the domain of translation studies should try to consider the actual translational decisions made by actual translators under different socio-cultural and ideological settings in real life and real situations, and explain the perlocutionary consequences resulted from adoption of such decisions. The novel "The old man and the Sea" is full of ideological loaded terms. It is on the part of translators to extract them and have knowledge about the characteristics of the author as well as the actors in his novel to decide the appropriate method for rendering. The two translations that the researchers have examined were mainly semantic translation, the first one try to foreignize the translation and the second one try to domesticate it for the readers with less attention to the ideological aspects of words. The researchers proposes more communicative approach for making the thought, ideological and cultural content of the original more accessible to the reader as well as semantic translation to preserve its local flavor.

Such a kind of study can be used to guide future researches toward comparing and distinguishing ideological considerations in different languages while translating literary texts. It might also be useful to consider a more purely cultural and interpretive analysis of translated texts. Another area for future research would be to replicate this study in other cultural contexts in order to gain a solid understanding of the role of culture in translating ideological laden terms. Another study that could be carried out in the future is a much more comprehensive one that would include all the translated versions of the novel "The Old Man and the Sea". In addition, the findings of the present study may have more implications for critical discourse studies, linguistics, literary studies, and translation studies. 


\section{References}

Bassnett, S. \& Lefevere, A. (eds.) (1998). Constructing Cultures: Essays on LiteraryTranslation. Multilingual Matters: Clevedon.

Calzada-Pérez, M. (2003). Introduction. In M. Calzada-Pérez (Ed.) Apropos of ideology (1-22). Manchester: St. Jerome

Chesterman, A. (1998). Memes of Translation: The Spread of Ideas in Translation Theory. In: E. Crisafulli (Ed) (2004). The Vision of Dante: Cary's Translation of the Divine Comedy. UK: Troubador Publishing Ltd.

Crisafulli, E. (2004). The Vision of Danate: Cary's translation of the divine comedy. Troubador Publishing Ltd. Retrived From www. google.books.com. id=E41TVky6MgAC\&pg= PA39.

Faramarzi, M.T. (2006). Piremard va Darya (translation). Tehran: Negah Publishing.

Fawcett, P. (1998). Ideology and translation. In M. Baker (Ed.) Routledge encyclopedia of translation studies (106-111). London: Routledge.

Goatly, A. (2000). An Introduction Course book: Critical Reading and Writing. London: Routledge.

Hatim, B. (1997). Communication across Cultures: Translation theory and Contrastive Text Linguistics. Exeter: University of Exeter Press.

Hatim, B. \& Mason, I. (1997). The Translator as Communicator. London: Routledge

Hemingway, E. (1976). The Old Man and the Sea. London: Triad/Panther Books, Granada Publishing Ltd.

Hermans, T. (1985). The Manipulation of Literature: Studies in Literary Translation. London and Sydney: Croom Helm.

Landers, C. E. (2001). Literary Translation. A Practical Guide. Multilingual Matters, Topics in Translation 22. Toronto and Sydney: Clevedon, Buffalo.

Lefevere, A. (1985). Why Waste Our Time on Rewrites- The Trouble with Interpretation and the Role of Rewriting in an Alternative Paradigm. In Theo Hermans, ed., the Manipulation of Literature: Studies in Literary Translation .London: Croom Helm.

Lefever, A. (1992). Translation, Rewriting, and the Manipulation of Literary Fames. London/ New York: Routledge.

Lisans Tezi, Y. (2008). A Comparative Study of the Two Turkish Versions of the Old Man and the Sea. Retrieved from www. belgeler.com/blg/laxw.

Mennheim, K. (1994). Ideology and Utopia: An Introduction to the Sociol ogy of Knowledge. London \& New York: K. Paul, Trench, Trubner \& Co. Harcourt, Brace and Company

Mason, I. (1994). Discourse, Ideology and Translation. In Language, Discourse and Translation in the West and Middle East. Amsterdam and Philadelphia: John Benjamins Publishing Company.

Newmark, P. (1988a). A Textbook of Translation. Hertfordshire: Prentice Hall.

Newmark, P. (1988b). Approaches to Translation. Hertfordshire: Prentice Hall.

Robinson, D. (2001). Who Translates? Translator Subjectivities beyond Reason. Albany: State University of New York Press.

Sanchez, M. T. (2009). The Problems of Literary Translation: a Study of the theory and Practice of Translation from English to Spanish. Peter Lang. Retrived from www.books.google.com. Id=WePQuqUyOSAC

Schäffner, C. (2003). Third ways and new centres: Ideological unity or difference. In Calzada-Pérez, M. (Ed.) Apropos of ideology, pp. 23-42. Manchester: St. Jerome.

Shahin, D. (1979). Piremard va Darya (translation). Tehran: Zarin Publishing

Shafieie, S. \& Hatam A. H. (2009). A Comprative Study of "The Old Man and the Sea" with its two Persian Translations. Retrived from www.translationdirectory.com.

Schleiermacher, F. (2000). Sobre los diferentes métodos de traducir, trans. and com. Valentín García Yebra. Madrid: Gredos

Sertkan, K. (2007). The Ideology of Lexical Choices in the Turkish Translations of Oliver Twist.

Sidiropoulou, M. (2005). Identity and Difference: Translation Shaping Culture. Peter Lang Publishing. Retrieved From www. books.google.com. id=AFfHy0KLmUIC\&dq.

Tompson, J. B. (1984). Studies in the theory of ideology. University of California press. Retrived from www. books.google.com. id=zOFBVLqceJgc

Van Dijk, T. A. (1998). Ideology: A Multidisciplinary Approach. London: Sage

Venuti, L. (1995). The Translator's Invisibility. London: Routledge.

Venuti, L. (1998a). The scandals of translation: Towards an ethics of difference. London: Routledge. (117). London: Routledge. 